Trabajos y Comunicaciones, 2da. Época, No 46, e048, octubre 2017. ISSN 2346-8971

Universidad Nacional de La Plata.

Facultad de Humanidades y Ciencias de la Educación.

Departamento de Historia

\title{
Lyons, Martyn. Historia de la lectura y de la escritura en el mundo occidental, Editoras del Calderón, Buenos Aires, 2012, 429 páginas
}

\author{
Darío Daniel Mengual de Gracia * \\ * Facultad de Humanidades y Ciencias de la Educación - Centro de Historia Argentina y \\ Americana - Universidad Nacional de La Plata, Argentina I dariomengual@gmail.com
}

\begin{abstract}
Desde finales de los 70 y principios de los 80, los historiadores vienen experimentando un creciente interés por las cuestiones culturales. Este interés se asienta en un cambio de enfoque, donde "lo cultural" ya no solo se lo analiza en su dimensión abstracta u/o estética, sino también en su dimensión material. Gracias a esto, la investigación cultural ganó autonomía con respecto a otras áreas y adoptó un carácter transicional, al poder dar cuenta del paso de factores de índole conceptual al plano de lo concreto y de factores concretos al plano de las ideas. Así, el intento por explicar el cambio histórico incorporó nuevas aristas, fuentes y metodologías. De este proceso surgieron Benedict Anderson y su libro "Comunidades Imaginadas", donde analiza el surgimiento del nacionalismo por medio del Capitalismo de Imprenta y de una política cultural; Peter Burke, sobre todo por sus obras más teóricas, donde intenta explicar y definir los diferentes aspectos de la Historia Cultural; o Robert Darnton y Roger Chartier, cuyos trabajos significaron un gran avance en cuanto a la historia del libro y la cultura impresa durante la Revolución Francesa. El libro de Martyn Lyons no solo se inscribe en esta corriente, sino que es un claro deudor de los trabajos de estos dos últimos historiadores.
\end{abstract}

En "Historia de la lectura y de la escritura en el mundo occidental”, Lyons rechaza la definición tecnológica del concepto de "Sociedades de la Información” y postula que éste se da desde el Antiguo Egipto, ya que quienes controlaban y restringían el acceso a la información, eran los que ejercían el poder en estas sociedades.

Con esta idea en mente, el autor se apoyará en los trabajos de Stanley Fish, Pierre Bourdieu y Robert Darnton para definir el concepto de "lectura". El mismo es conceptualizado como un proceso de apropiación e interpretación, que se da en el plano estrictamente individual. No obstante, existe un mecanismo que evita la anarquización de la semántica que produce esta misma definición. Dicho mecanismo, consiste en que los lectores se agrupan en Comunidades Interpretativas (Stanley Fish), definidas por el Capital Económico y Cultural de sus miembros (Pierre Bourdieu) e insertas dentro del marco regulatorio del Circuito de la Comunicación (Robert Darnton), lo que determina la creación de un Habitus particular que “fija” el sentido para todos los miembros del grupo.

Recibido: 20 de julio de 2017 | Aceptado: 2 de septiembre de 2017 | Publicado: 23 de octubre de 2017

Cita sugerida: Mengual de Gracia, D. D. (2017).[Revisión del libro Historia de la lectura y de la escritura en el mundo occidental, por M. Lyons ]. Trabajos y Comunicaciones, 46, e048. https://doi.org/10.24215/23468971e048 
Este esfuerzo por dar una definición precisa del concepto de lectura, no tiene su correlato en el de escritura. Con respecto a este particular, el autor aduce que el carácter reciente de las investigaciones sobre la escritura, impide el ponerlas a la par de los trabajos más consolidados de historia de la lectura. Este desbalance quedará reflejado a lo largo del libro que, pese a titularse "Historia de la lectura y de la escritura en el mundo occidental", se desarrolla más como una historia de la lectura con aportes esporádicos de historia de la escritura.

Hecho esto, Lyons expresará cuatro intenciones que darán forma al recorte, a la estructura y al tipo de análisis del libro. Ellas son: a) Encontrar al lector/público deseado por el autor o el editor; b) Encontrar al lector real y sus respuestas; c) Contextualizar históricamente el encuentro entre el lector y el texto; d) Demostrar la democratización de las prácticas de escritura en todas sus ramificaciones.

Esta puntualización determinará, por ejemplo, que el recorrido histórico que trazará la obra, no esté marcado predominantemente por la cronología. Por el contrario, el texto se va estructurando y desenvolviendo por medio de una serie de puntos de inflexión, algunos de naturaleza tecnológica y otros de naturaleza formal, que recorren la historia de la lectura desde la Antigüedad hasta los 2000.

A esto también corresponde la causa de que, pese a que el texto se remonta hasta la Grecia Clásica y cuenta con trece capítulos, el mayor peso conceptual y narrativo recae en los apartados que versan sobre cuestiones vinculadas a la Modernidad. Esto también puede ser atribuible a la propia trayectoria del autor, quien ha desarrollado su carrera como un historiador de la lectura de Europa, durante la transición entre el Antiguo Régimen y la Modernidad.

Pese a las salvedades pertinentes, el libro tiene un claro desbalance hacia las cuestiones de la Modernidad, que se prefigura desde el capítulo 3, pero se ve con mayor claridad en el capítulo 6. Este desbalance hacia la Modernidad, solo se abandonará a medias en el capítulo 13, donde se analizan cuestiones que algunos pensadores consideran propias de la Posmodernidad y otros de la Modernidad Líquida.

Dejando de lado el capítulo 1, de claro corte introductorio, se puede establecer una primera división que incluye a los capítulos 2, 3, 4 y 5. Esta división, realizada por nosotros a los efectos del análisis, se justifica en el desbalance temático al que se hizo referencia con anterioridad. En dichos capítulos, el autor se preocupa por señalar la aparición de una serie de hitos tecnológicos, como la invención del pergamino, del códice o de la imprenta, e innovaciones formales, como la lectura silenciosa, el uso de espacios entre palabras y los signos de puntuación.

En definitiva, los capítulos 2, 3, 4 y 5 retratan de manera procesual, la forma en que se constituyeron los elementos que, bajo otras coyunturas económicas, sociales y políticas, dieron origen a la lectura en su acepción moderna. Esta acepción moderna, no es más que la lectura entendida como un proceso individual, democrático y extensivo de apropiación y re-significación semántica.

Aun cuando Lyons tiene especial cuidado, en evitar caer en reduccionismos explicativos y en no salirse de la línea historiográfica historicista, los capítulos 2, 3, 4 y 5 se desarrollan muy rápido. Baste de decir que en el capítulo 2 - “La lectura y la escritura en el mundo antiguo y medieval”-, condensa la perspectiva sobre la Edad Antigua, solamente en la Grecia Clásica y la Roma Tardo-Republicana, y sobre la Edad Media en las antiguas zonas de influencia carolingia.

Otro tanto ocurre en los capítulos 3 — “La imprenta, ¿Fue realmente una revolución?”-, 4 — “La imprenta y la reforma protestante" - y 5 - "Los libros del renacimiento y los lectores humanistas"- . Luego de solo un capítulo para desarrollar la historia previa, el autor profundiza en el Renacimiento, siguiendo el eje del impacto de la presencia de la imprenta de tipos móviles. El efecto general, es que nuevamente se condensa la perspectiva sobre el Renacimiento a unos pocos factores, como lo es la Reforma, la Contrarreforma y el Humanismo, y se deja de lado a otros, como el Circuito de la Comunicación o las Comunidades Interpretativas.

A partir del capítulo 6, podemos establecer unilateralmente, una segunda etapa que se extenderá hasta el capítulo 12. Aquí, Lyons se adentra en el proceso de construcción de las prácticas de lectura y escritura modernas, 
manteniéndose en el historicismo y evitando caer en reduccionismos explicativos y en antinomias conceptuales irresolubles. Sin embargo, esta etapa estará marcada por su mayor grado de especificidad en el proceso tratado. Esto se hace evidente en la mayor cantidad de matices y combinaciones explicativas, que el autor será capaz de realizar, en términos relativos.

Los siete capítulos mencionados, representan más de la mitad del volumen total del texto. Como característica general de éstos, se puede decir que el predominio del concepto de lectura, continuará eclipsando al de escritura.

Con respecto al área de muestreo, tampoco se puede asimilar enteramente a la categoría de "mundo occidental", ya que el relevamiento de datos se concentra principalmente en Francia y Gran Bretaña; España -ocasionalmentey Estados Unidos -sobre todo, para finales del siglo XIX y principios del XX-.

El carácter eminentemente moderno por el que están cruzados los capítulos seleccionados, se hace evidente tras su análisis. El capítulo 6 - “La imprenta y la cultura popular”-, analiza una serie de procesos de apropiación y resignificación semántica, de corte netamente individual, cuya conjunción determina la presencia siempre difusa de la Cultura Popular. El paradigma de este tipo de procesos, es el caso de Domenico Scandella, un molinero friulano condenado por herejía y muerto en la hoguera en el siglo XVII. El Capítulo 7 — "El ascenso de la alfabetización en la Edad Moderna, los siglos XVII y XVIII”-, analiza el proceso al que hace referencia el título, como algo externo a las instituciones formales y ejecutado por el esfuerzo individual de quienes querían acceder a la cultura. En el Capítulo 8 - “La censura y el público lector de la Francia prerrevolucionaria”- se trata a la censura como una actividad portadora de regulaciones contradictorias, por lo que, en la práctica, un individuo podía beneficiarse de esto para convertirse en un verdadero self-made man. El paradigma que el autor presenta para el proceso, es el caso del editor Charles-Joseph Panckoucke, un editor francés del siglo XVIII que construyó su fortuna manipulando el régimen de censura. El Capítulo 9 - “La fiebre de la lectura, 1750-1830”-, básicamente consiste en el surgimiento de una "República de las Letras" formada por lectores claramente modernos. El Capítulo 10 — “La época de la lectura de masas”-, está entroncado con el anterior, y consiste en como una serie de cambios tecnológicos, abarataron los costes y democratizaron el acceso a la literatura moderna. En el Capítulo 11 — “Nuevos lectores y nuevas culturas lectoras”-, se analiza la incorporación de las clases bajas al mercado editorial, lo que constituyó la edad de oro de los libros. Por último, en el Capítulo 12 — "La democratización de la escritura, desde 1800 hasta la actualidad”-, se analiza específicamente la escritura. La forma en que lo hará es, principalmente, por medio de los ego-documentos, por lo que también se tratará de una noción de escritura esencialmente moderna.

En este punto podemos situar una tercera división analítica, compuesta exclusivamente por el capítulo 13 — “Los lectores y escritores en la era digital”- Este capítulo sitúa su línea de análisis entre la segunda mitad del siglo XX y el 2000, principalmente en Estados Unidos, y analiza tanto la lectura como la escritura. Esto lo hace siguiendo la premisa de que, las nuevas herramientas ofimáticas, otorgaron al lector la capacidad de maquetar y editar textos. Además, internet permite saltar las restricciones de copyright, difuminándose la figura del editor.

En el capítulo 13, es donde más se hace evidente el carácter historicista de la obra, debido a que lo reciente del proceso reduce el acervo de estudios realizados. Ante esta relativa escasez de material académico, el autor, en lugar de refugiarse en la ideología o solapar una crítica esencialista a la época, busca reconstruir las causalidades en el devenir histórico y sustenta sus conclusiones en el trabajo de otros investigadores, como es el caso de Jeanette Gilfedder. Si bien lo mencionado reviste un carácter axiomático, no es menos cierto que suele difuminarse formalmente, cuanto más reciente es el proceso analizado, de allí que el esfuerzo de Lyons sea notable.

A modo de cierre, se podría decir que "Historia de la lectura y de la escritura en el mundo occidental”, es un libro riguroso y, a la vez, fácil de leer. Riguroso, porque se desarrolla por medio de hitos formales y tecnológicos verificables, y se asienta en la literatura académica previa sobre el tema. Paradójicamente, al tener esto como un axioma, se genera cierta debilidad en los contenidos. 
Cuando un autor individual ajusta su perspectiva, en función del acervo documental y académico sobre el tema, su visión tenderá a focalizarse en sus particulares áreas de interés y conocimiento. Esto es lo que ocurre en este libro. Lyons conoce y tiene interés en el surgimiento de la lectura moderna europea, con lo que los capítulos vinculados a esta temática tienen mayor peso. Sin embargo, la existencia de este desbalance hacia las cuestiones de la Modernidad, no se traduce en una debilidad argumental. Por el contrario, el aparato erudito es muy consistente. El desbalance, únicamente se manifiesta, en que el autor no agota todas las posibilidades de análisis que ofrecen las temáticas pre-modernas.

Por todo lo dicho el libro de Martyn Lyons resulta atractivo, consistente y con una narrativa ágil, que hacen del mismo un texto destacable. 